\title{
Low glucose under hypoxic conditions induces unfolded protein response and produces reactive oxygen species in lens epithelial cells
}

\author{
R Elanchezhian ${ }^{1}$, P Palsamy ${ }^{1}$, CJ Madson ${ }^{1}$, ML Mulhern ${ }^{1}$, DW Lynch ${ }^{1}$, AM Troia ${ }^{1}$, J Usukura ${ }^{2}$ and T Shinohara ${ }^{\star, 1}$
}

Aging is enhanced by hypoxia and oxidative stress. As the lens is located in the hypoglycemic environment under hypoxia, aging lens with diabetes might aggravate these stresses. This study was designed to examine whether low glucose under hypoxic conditions induces the unfolded protein response (UPR), and also if the UPR then generates the reactive oxygen species (ROS) in lens epithelial cells (LECs). The UPR was activated within $1 \mathrm{~h}$ by culturing the human LECs (HLECs) and rat LECs in $<1.5 \mathrm{mM}$ glucose under hypoxic conditions. These conditions also induced the Nrf2-dependent antioxidant-protective UPR, production of ROS, and apoptosis. The rat LECs located in the anterior center region were the least susceptible to the UPR, whereas the proliferating LECs in the germinative zone were the most susceptible. Because the cortical lens fiber cells are differentiated from the LECs after the onset of diabetes, we suggest that these newly formed cortical fibers have lower levels of Nrf2, and are then oxidized resulting in cortical cataracts. Thus, low glucose and oxygen conditions induce the UPR, generation of ROS, and expressed the Nrf2 and Nrf2-dependent antioxidant enzymes at normal levels. But these cells eventually lose reduced glutathione (GSH) and induce apoptosis. The results indicate a new link between hypoglycemia under hypoxia and impairment of HLEC functions. Cell Death and Disease (2012) 3, e301; doi:10.1038/cddis.2012.40; published online 19 April 2012

Subject Category: Experimental Medicine

Diabetic cataracts are characterized by cortical or posterior sub-capsular (PSC) opacities, and in adults the opacities are known to be due to an acceleration of age-related cataracts (ARCs). ${ }^{1}$ Cataractous lenses have decreased epithelial cell density and extensive cellular damage in the cortical region of the lens. ${ }^{2}$ It has been reported that an accumulation of sorbitol under hyperglycemic conditions can generate osmotic stress, ${ }^{3}$ and the osmotic stress combined with oxidation, ${ }^{4}$ for example, glycoxidation, increased cytosolic calcium, ${ }^{5,6}$ cell death and aging, ${ }^{1,7}$ is considered to be the cause of diabetic cataracts. $^{8}$

The lens is an avascular organ, and it receives glucose and oxygen from the ciliary body and blood vessels of the iris. The level of glucose in the aqueous fluid is $2-4 \mathrm{mM}$ and that in the vitreous fluid is $\sim 1.6 \mathrm{mM} .{ }^{9}$ Although intensive insulin therapy is aimed at strictly controlling the glucose level, it can also cause an increase in the incidence of severe hypoglycemia by 4-6-folds. ${ }^{10}$ If the lens is deprived of glucose for $48 \mathrm{~h}$, a nuclear cataract can develop. ${ }^{11}$ This cataract bears a striking resemblance to the hypoglycemic cataract seen in children. $^{12}$
The lens is also located in a hypoxic environment of $0.5-2.3 \%$ oxygen. ${ }^{13-15}$ The oxygen level in the vitreous body of cataract patients is $0.1-0.5 \%,{ }^{16}$ and that in the anterior vitreous immediately adjacent to the lens is reported to be $0.26-0.40 \%$ in cats, rabbits, and chickens. ${ }^{15,17}$ An environment of $0.1-1.0 \%$ oxygen is defined as being severely hypoxic. The oxygen level in the ocular lens can easily fall into the severe hypoxic range even in a 13-15\% atmospheric oxygen environment, ${ }^{18}$ for example, in diabetic patients. ${ }^{19}$ Similar low levels can develop during the progression of arteriosclerosis. ${ }^{20}$

In addition to the individual levels of glucose and oxygen, the ratio of glucose/oxygen is important and excess levels of either oxygen or glucose can lead to oxidization of the lens. Importantly, normal lenses acquire about $75-80 \%$ of their ATP from anaerobic and $20-25 \%$ from aerobic respiration. ${ }^{20}$

Non-physiological glucose concentration such as near $0 \mathrm{mM}$ and more than $250 \mathrm{mM}$ of glucose in a $20 \%$ atmospheric oxygen environment induce the chronic unfolded protein response (UPR). ${ }^{21}$ Recent paper reported that aging is associated with hypoxia and oxidative stress. ${ }^{22}$ However,

\footnotetext{
${ }^{1}$ Department of Ophthalmology and Visual Sciences, University of Nebraska Medical Center, Omaha, NE, USA and ${ }^{2}$ Eco Topia Science Institute, Nagoya University, Nagoya, Japan

*Corresponding author: T Shinohara, Department of Ophthalmology and Visual Sciences, University of Nebraska Medical Center, Omaha, NE 68198, USA. Tel: 402-559-4205; Fax: 402-559-3869; E-mail: tshinohara@unmc.edu

Keywords: hypoxia; low glucose; Nrf2; reactive oxygen species; UPR

Abbreviations: ARC, age-related cataract; ATF4, activating transcription factor 4; BrdU, 5-bromo-2-deoxyuridine; CHOP, C/EBP-homologous protein; DMEM, Dulbecco's modified Eagle's medium; P-elF2 $\alpha$, phosphorylated eukaryotic translation initiation factor $2 \alpha$; EthD, ethidium homodimer- 1 ; Ero1 $\mathrm{L} \beta$, endoplasmic reticulum oxidoreductin 1-L $\beta$; ER, endoplasmic reticulum; FCS, fetal calf serum; GAPDH, glyceraldehyde 3-phosphate dehydrogenase; GF-DMEM, glucose free DMEM; $\mathrm{GR}$, glutathione reductase; $\mathrm{GSH}$, reduced glutathione; $\mathrm{H}_{2}$-DCFH, $2^{\prime}, 7^{\prime}$-dichlorodihydrofluorescein diacetate; HLEC, human lens epithelial cells; $\mathrm{P}$-IRE1, phosphorylated inositol requiring enzyme-1; Nrf2, nuclear factor-erythroid-2-related factor 2; LEC, lens epithelial cells; PDI, protein disulfide isomerase; PERK, PKR-like endoplasmic reticulum kinase; PSC, posterior sub-capsular cataract; ROS, reactive oxygen species; UPR, unfolded protein response
}

Received 13.12.11; revised 24.2.12; accepted 12.3.12; Edited by M Federici 


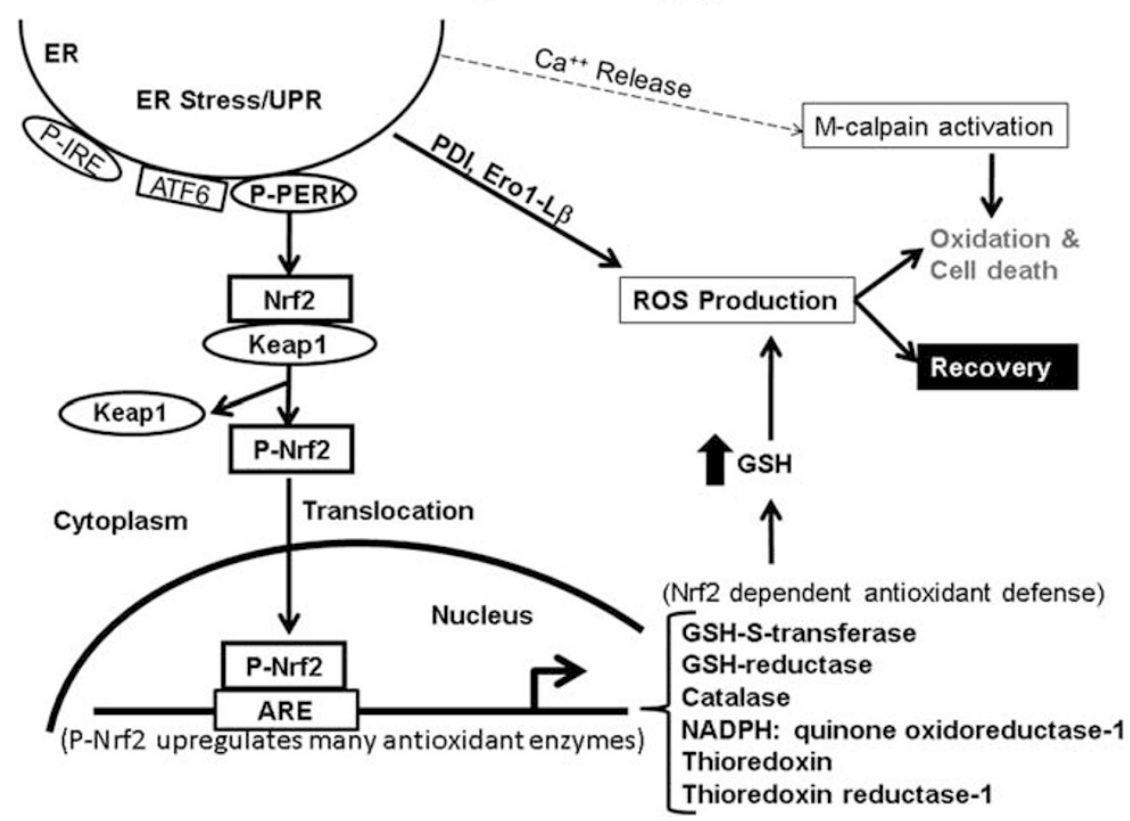

Figure 1 A schematic diagram of our working hypothesis. Cataractogenic stress induces the UPR. ${ }^{40}$ The UPR is a protective mechanism against ER stress, and its activation leads to phosphorylation of PERK (P-PERK). Prolonged or severe ER stress induces the apoptotic UPR, which generates excess levels of ROS and activates M-calpain. P-PERK phosphorylates Nrf2, the P-Nrf2 dissociates from Keap1 and translocates into the nucleus to bind to the antioxidant response element (ARE), which activates the transcription of more than 20 antioxidant enzymatic genes such as, glutathione, GR, thioredoxin, thioredoxin-S-transferase, and catalase. These antioxidant enzymes regenerate GSH, and the resultant GSH eliminates ROS to survive or recover from the stress. We hypothesized that low glucose under hypoxic condition suppresses the levels of Nrf2, which downregulates the antioxidant enzymes and GSH and results in oxidation of the lens. Thus, low glucose under low oxygen stress activates the UPR, production of ROS, and dysfunction of the antioxidant defense protection leading to lens oxidation

there is no information on whether hypoglycemic conditions under in situ hypoxic concentrations ( $<1 \%$ oxygen) can induce the UPR in the lens. The UPR is a protective mechanism that is activated by phosphorylation of PKR-like endoplasmic reticulum kinase (PERK), inositol requiring enzyme-1 (IRE-1), and eukaryotic translation initiation factor $2 \alpha$ (elF2 $\alpha$ ). All of these components are the initial cellular response to stress. However, chronic UPR induces apoptosis by activating ATF4 and death factors such as, C/EBPhomologous protein $(\mathrm{CHOP})^{23}$ and caspase-12. ${ }^{24}$ ATF4 is identified as an important regulator of mammalian lens development. ${ }^{25}$ The lens-specific expression of ATF4 in the mutant mice demonstrates its importance in the later stages of lens fiber cell differentiation. ${ }^{26}$ The UPR also generates excess levels of reactive oxygen species (ROS). ${ }^{27}$ The ROS are generated by disulfide formation in the ER which is driven by a protein relay ${ }^{27}$ involving a protein disulfide isomerase (PDI) and ER oxidoreductin 1 (Ero1)-L $\alpha$, and $-\mathrm{L} \beta{ }^{28}$ The terminal electron acceptor is molecular oxygen. In the UPR, the PDI level is constant but the level of $E$ ro1-L $\beta$ is increased and Ero1-L $\alpha$ is decreased. In addition, decreased levels of cytosolic-free GSH from the mitochondria are an additional source of ROS. ${ }^{7}$

To counteract the ROS, the UPR activates a PERKdependent antioxidant defense system and upregulates Nrf2, a master transcription factor for more than 20 antioxidant genes such as, glutathione reductase (GR), thioredoxin, thioredoxin-S-transferase, and catalase (Figure 1). . $^{29,30}$

We hypothesized that low glucose under hypoxic condition in LECs induces the UPR, which leads to the production of
ROS, although the Nrf2-dependent antioxidant defense protection might fail during low glucose. To test this hypothesis, we studied the UPR induction, ROS production, and evaluated the levels of Nrf2 in HLECs treated with low glucose under low oxygen levels.

\section{Results}

Glucose and oxygen levels in cell culture medium. To estimate the consumption of glucose, HLECs in 10-cm Petri dishes at $80 \%$ confluence were incubated in 1 or $2 \mathrm{mM}$ glucose-DMEM under $1 \%$ atmospheric oxygen. After 2, 4, 6, and $8 \mathrm{~h}$, the glucose concentration in the culture medium was measured. The consumption of glucose by the HLECs under our culture conditions was $1 \mathrm{mM} / \mathrm{Petri}$ dish/8 $\mathrm{h}$ or $1.0 \mathrm{nM} / \mathrm{cell} /$ $8 \mathrm{~h}$ both in $1 \mathrm{mM}$ or $2 \mathrm{mM}$ glucose-DMEM (Figure 2a). We also measured the oxygen levels in air, culture medium, and culture medium containing $1 \times 10^{6}$ HLECs (10-cm Petri dish) placed in the vaccuum bag containing oxygen absorption chemicals, AnaeroGen (Oxoid Ltd, Haunts, UK). The oxygen level in the air of the vacuum bag was reduced to severe hypoxia levels $(<0.14 \%)$ within $1 \mathrm{~h}$, in the culture medium with HLECs within $2 \mathrm{~h}$, and in the culture medium without cells within $4.5 \mathrm{~h}$ (Figure $2 \mathrm{~b}$ ). Therefore, to achieve severe hypoxic conditions required at least $2 \mathrm{~h}$ under our experimental conditions.

Low level of glucose under severe hypoxic condition activates UPR. When HLECs were cultured in GF-DMEM under $0.14 \%$ oxygen, the UPR was strongly activated. 

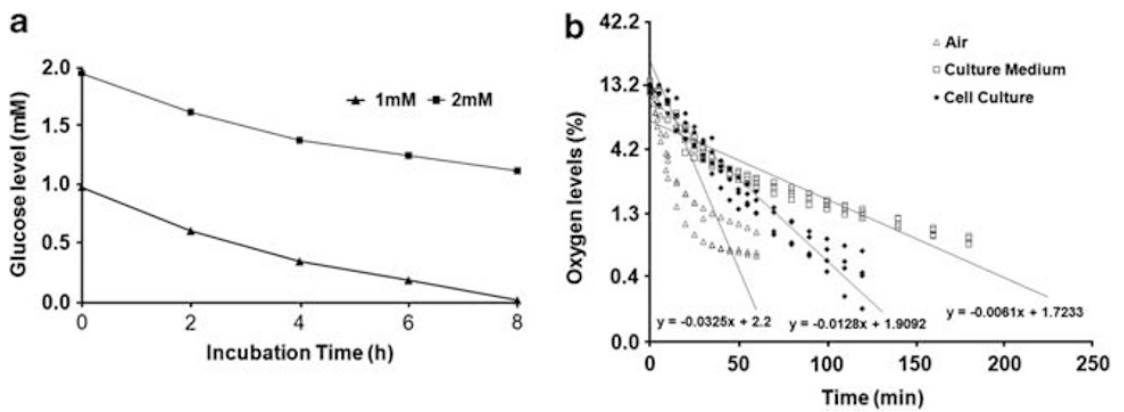

Figure 2 Consumption of glucose by HLECs, and levels of oxygen in the air of the vacuum bag and culture medium. (a) Glucose level was measured in HLECs cultured in DMEM containing $1 \mathrm{mM}$ and $2 \mathrm{mM}$ glucose at $1 \%$ atmospheric oxygen every $2 \mathrm{~h}$. (b) Oxygen level was measured in the air of the vaccuum bag containing AnaeroGen $(\Delta)$, in $25 \mathrm{mM}$ glucose-DMEM alone $(\square)$, and in $25 \mathrm{mM}$ glucose-DMEM with $1.5 \times 10^{6} \mathrm{LECs}(\bullet)$. Each point represents a measurement. The linear regression was determined with a computed prediction

Because lenses of the elderly are reported to be surrounded by $0.1-0.5 \%$ atmospheric oxygen, ${ }^{16}$ we then asked how long it would take HLECs in GF-DMEM to activate the UPR under severe hypoxic conditions. To answer this, we cultured HLECs for $0,0.5,1.5,2.5$, and $4.5 \mathrm{~h}$ in GF-DMEM under severe hypoxic conditions. We found that duration of $0.5 \mathrm{~h}$ and $1.5 \mathrm{~h}$ was sufficient to induce the phosphorylation of PERK and elF2 $\alpha$ (Figure 3a). These results suggested that HLECs exposed to GF-DMEM at $0.14 \%$ oxygen is sufficient to induce a strong UPR, and even stronger phosphorylation developed is after 2.5 and $4.5 \mathrm{~h}$ (Figure 3a). In preliminary experiments, we found that HLECs cultured in GF-DMEM under 4 or $20 \%$ atmospheric oxygen activated only a very mild UPR. On the other hand, when the HLECs were cultured under severe hypoxic conditions $\left(0.14 \% \mathrm{O}_{2}\right)$, with $5 \mathrm{mM}$ or $25 \mathrm{mM}$ glucose, no apparent UPR was induced within $24 \mathrm{~h}$ (Supplementary Figure S1). Thus, the UPR was strongly induced only under combined low glucose and low oxygen conditions in HLECs in $24 \mathrm{~h}$

Critical concentrations of glucose and oxygen to induce the UPR. Next, we determined the lowest concentration of glucose that would induce the UPR in HLECs. The cells were cultured in GF-DMEM (Figure 3a), $1 \mathrm{mM}$ glucose-DMEM, and $2 \mathrm{mM}$ glucose-DMEM under $1 \%$ atmospheric oxygen for $0,2,4,6$, and $8 \mathrm{~h}$ (Figures $3 \mathrm{~b}-\mathrm{d}$ ). During these culture periods, glucose is consumed by the cells, and the levels decreased from 1 to $0 \mathrm{mM}$ (Figure 3c) or from 2 to $1 \mathrm{mM}$ (Figure 3d). Then, we examined the phosphorylation of PERK and elF2 $\alpha$ by sampling the HLECs after 2, 4, 6, and $8 \mathrm{~h}$ of incubation. Protein blot analysis showed that increased levels of P-PERK and P-elF2 $\alpha$ after $4 \mathrm{~h}$ in GF-DMEM and $1 \mathrm{mM}$ glucose-DMEM. These results indicated that both GF-DMEM and $1 \mathrm{mM}$ glucose-DMED induced the phosphorylation of PERK and elF2 $\alpha$ after $4 \mathrm{~h}$. Thus, $1 \mathrm{mM}$ of glucose can induce the UPR and $4 \mathrm{~h}$ was required to accumulate detectable levels of P-PERK and P-elF2 $\alpha$. In contrast, HLECs cultured in $2 \mathrm{mM}$ glucose-DMEM induced the UPR after $8 \mathrm{~h}$ of incubation. This suggested that there is sufficient glucose after $4 \mathrm{~h}$ of culture, which does not activate the UPR, but thereafter when the glucose concentration has decreased to $1.5 \mathrm{mM}$ or less it would induce the UPR. These results further indicated that glucose concentration less than $1.5 \mathrm{mM}$ induces the UPR in cultured HLECs under $1 \%$ atmospheric oxygen.

Activation of UPR in rat LECs by ischemia. Under ischemic conditions, the oxygen level in the eye is reduced very rapidly but the glucose level remains normal for relatively longer times. ${ }^{35}$ Thus, ischemia might be a condition to study the effects of hypoxic condition on lenses. To accomplish this, four groups of three rats each were euthanized by $\mathrm{CO}_{2}$ inhalation, and the right eyes were immediately removed and the left eyes were kept in the rats for 1 and $3 \mathrm{~h}$ at $37^{\circ} \mathrm{C}$. The glucose level in the vitreous and anterior chamber decreased from 3.6 to $0.7 \mathrm{mM}$ after $1 \mathrm{~h}$ and $0.8 \mathrm{mM}$ after $3 \mathrm{~h}$ after the rats were euthanized. These findings are consistent with those of bovine eyes. ${ }^{35}$ The oxygen levels in the anterior chamber dropped below $0.19 \%$ within $6 \mathrm{~min}$ after the rats were euthanized and to $0.15 \%$ after $1 \mathrm{~h}$ and $0.16 \%$ after $3 \mathrm{~h}$ (Figure $4 \mathrm{a}$ ). Thus, the oxygen level sharply dropped but the glucose levels decreased more slowly. These findings showed that this is a good model to study the effects of oxygen in the induction of the UPR in sthe lens.

Lenses were then isolated from the ischemia-treated rat eyes for 1 and $3 \mathrm{~h}$. Protein blot analyses of LECs in these rat lenses showed that P-PERK, P-elF $2 \alpha$, and P-IRE-1 were significantly upregulated after $1 \mathrm{~h}$ of hypoxia (Figure $4 \mathrm{~b}$ ). Our results showed that $0.8 \mathrm{mM}$ glucose and less than $0.19 \%$ of oxygen for $1 \mathrm{~h}$ were sufficient to induce the UPR in rat LECs.

UPR activation continues after removal of low glucose conditions. HLECs cultured in GF-DMEM and placed in the AnaeroGen vaccuum bag for less than $1.5 \mathrm{~h}$ and then returned to the normal culture conditions $(5 \mathrm{mM}$ glucoseDMEM in $4 \%$ atmospheric oxygen) for $20 \mathrm{~h}$ did not produce ROS and apoptosis (Figure 5a). However, when the LECs were treated for more than $1.5 \mathrm{~h}$ and then returned to normal culture conditions for $20 \mathrm{~h}, 5-10 \%$ of these HLECs produced ROS and apoptosis in the LECs (Figure 5a). These results indicated that the protective UPR was activated by $0.5-1.5 \mathrm{~h}$ of GF-DMEM, but the apoptotic UPR was activated in a relatively small number of LECs 

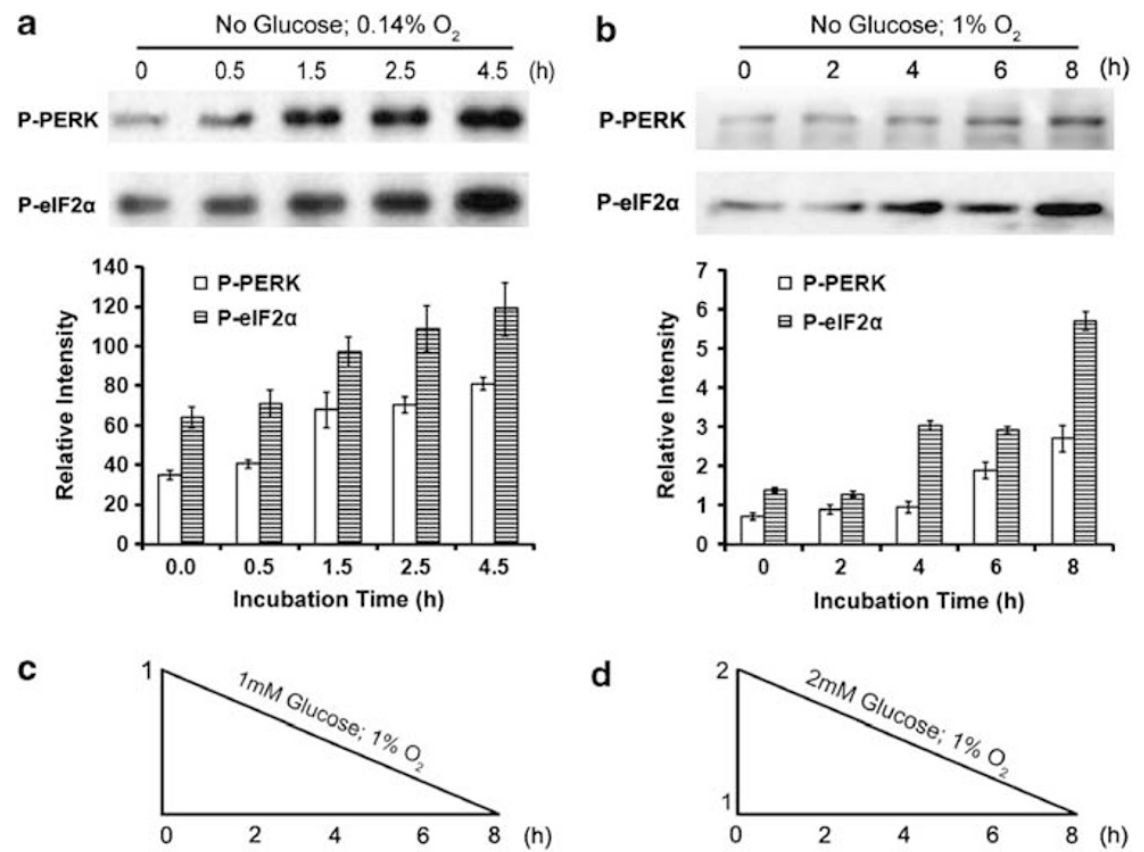

d

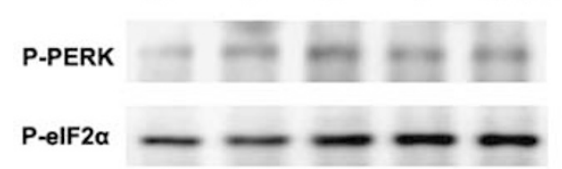

)

d
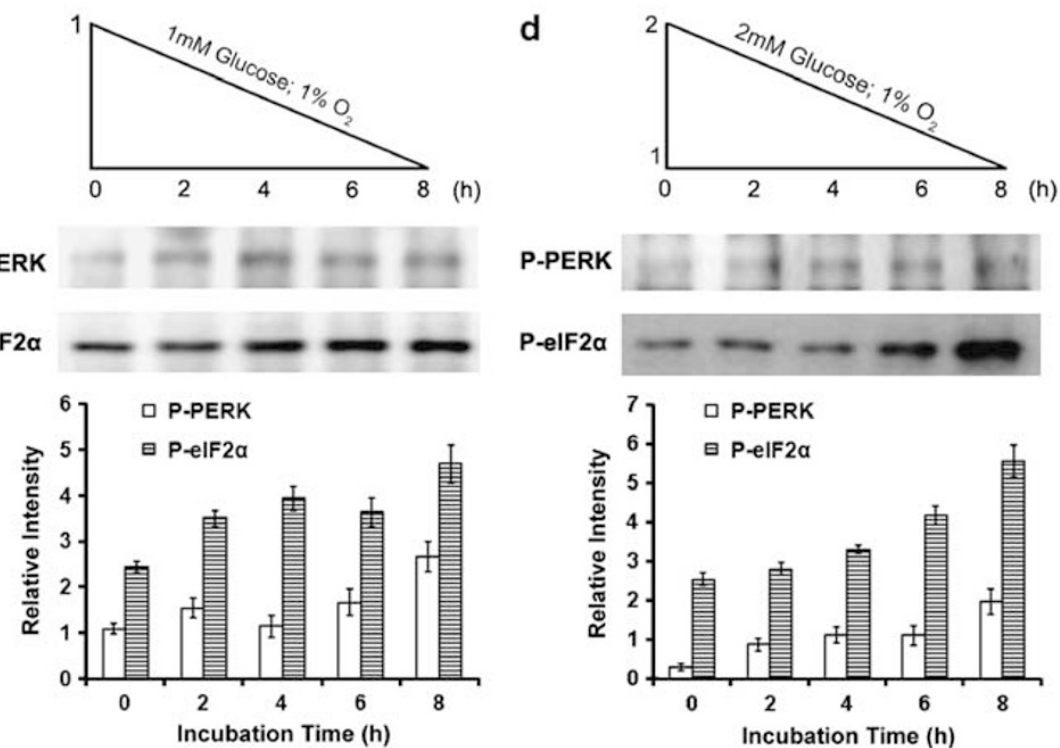

Figure 3 Activation of UPR by phosphorylation of PERK and elF2 $\alpha$ in human LECs. (a) Representative western blots of P-PERK and P-elF2 $\alpha$ of human LECs cultured in GF-DMEM for $0.5,1.5,2.5$, and $4.5 \mathrm{~h}$ at $<0.14 \%$ atmospheric oxygen. (b-d) Representative western blots of P-PERK and P-elF2 $\alpha$ of human LECs cultured in GF-DMEM (b), $1 \mathrm{mM}$ glucose-DMEM (c), and $2 \mathrm{mM}$ glucose-DMEM (d) for $0,2,4,6$, and $8 \mathrm{~h}$ at $1 \%$ atmospheric oxygen. Protein expressions were normalized to intensity of GAPDH expression. The results are the means \pm S.D.s of three experiments for each protein

when the HLECs were exposed to longer durations ( $>1.5 \mathrm{~h}$ ) of the hypoxic conditions.

To confirm this UPR activation, HLECs were cultured for 3 or $5 \mathrm{~h}$ in GF-DMEM in the AnaeroGen vaccuum bag, return to $5 \mathrm{mM}$ glucose-DMEM, and then cultured for $1,6,14,17$, and $20 \mathrm{~h}$ under $1 \%$ atmospheric oxygen. We assayed for the levels of the Nrf2, glutathione reductase (GR), and catalase in the HLECs cultured for $0,1,6,14,17$, and $24 \mathrm{~h}$ by protein blot analysis. One striking finding was that the level of Nrf2, GR, and catalase were significantly increased in HLECs treated for $3 \mathrm{~h}$ (Figure 6a). These results indicated that HLECs treated for $3 \mathrm{~h}$ activated the survival UPR to protect cells from stress by increasing Nrf2, GR, and catalase. In contrast, HLECs treated for $5 \mathrm{~h}$ (clock time) induced the apoptotic UPR and significant levels of the production of ROS and resulted in apoptosis (Figure 6b).
Proliferating HLECs are more susceptible to low glucose and low oxygen conditions. Next, we asked what type of LECs becomes apoptotic among all the LEC types cultured in GF-DMEM under hypoxic conditions. We hypothesized that proliferating cells might be more susceptible to the UPR. To test this, HLECs were exposed to BrdU for $30 \mathrm{~min}$, and the cells were washed and cultured in GF-DMEM for an additional $15 \mathrm{~h}$ in $4 \%$ atmospheric oxygen. At the end of the culture period, the cells were stained with EthD and a fluor-labeled antibody to BrdU.

The results showed that about $5 \%$ of cells were BrdUand EthD-positive and more than $78 \%$ of these cells were co-stained (Figure $5 \mathrm{~b}$ ). These results clearly indicated that the proliferating cells were the cells most susceptible to the UPR-dependent cell death. These findings are consistent with those of Endo et al. ${ }^{36}$ 
a Glucose $(\mathrm{mM}) \quad 3.6 \quad 0.7 \quad 0.8$ Oxygen $(\%)<0.19<0.15<0.16$

b
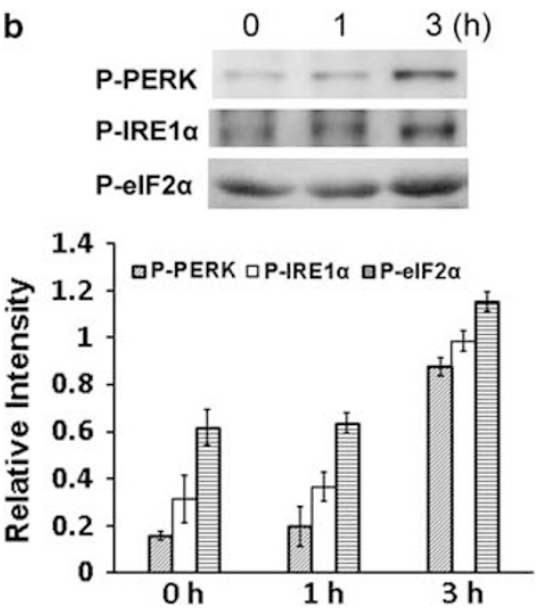

Figure 4 Expression of UPR-specific proteins in rat LECs. (a) The glucose and oxygen levels present in the anterior chamber were measured at 0,1 and $3 \mathrm{~h}$ after killing the rats and the respective values were presented. (b) Representative western blot of P-PERK, P-IRE $1 \alpha$, and P-elF2 $\alpha$ of rat lens exposed to ischemic conditions for 1 and $3 \mathrm{~h}$. Intensity of each band was normalized with GAPDH
Similarly, rat lenses subjected to ischemia for 1 or $5 \mathrm{~h}$ were reperfused with $5 \mathrm{mM}$ glucose-DMEM in under $1 \%$ atmospheric oxygen for $22 \mathrm{~h}$. The production of ROS and cell death in the treated and untreated control lenses was determined. The lenses exposed to ischemic conditions for $1 \mathrm{~h}$ had very few ROS-producing cells in the germinative zone of LECs and no apoptotic cells (Figure 7a). Neither ROS nor apoptotic cells were found in the untreated control LECs. On the other hand, lenses treated with ischemia for $5 \mathrm{~h}$ had ROS that were found predominantly in the peripheral and cortical LECs of all lenses (Figure 7b). In contrast, we found very few apoptotic cells in these lenses. These results indicated that the proliferating cells in the germinative zone were most sensitive to hypoglycemic insults under hypoxia, and these conditions activated the UPR. Although brain and cardiac cell die after 4-9 min of anoxia, LECs have an unusually strong tolerance to ischemic insults.

Loss of GSH in HLECs cultured in GF-DMEM under $0.14 \%$ oxygen. There is no information on how much GSH is decreased in HLECs treated with GF-DMEM under severe hypoxic conditions. This is relevant because GSH is oxidized rapidly in the presence of $\mathrm{ROS}$. Initially, we examined the
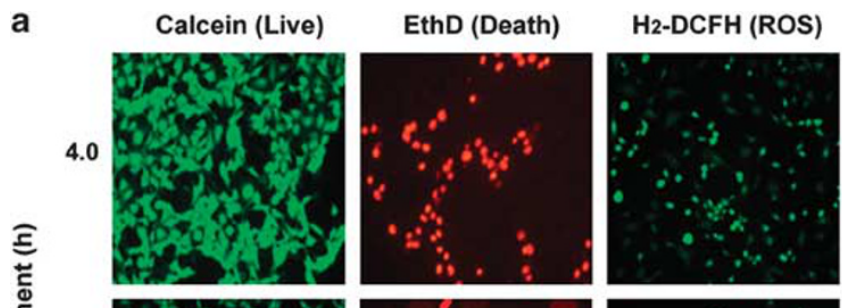

b
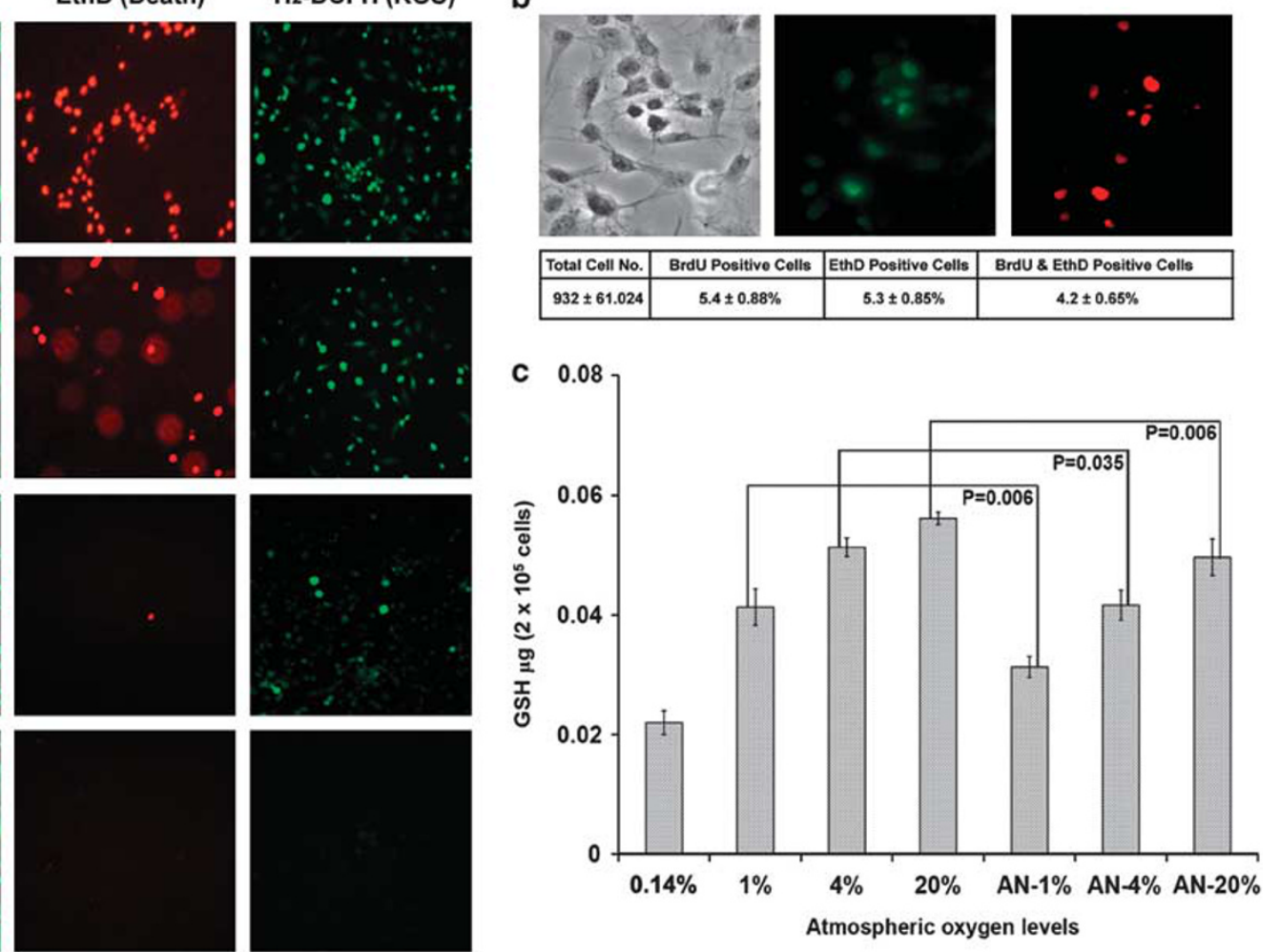

Figure 5 Responses of HLECs against low glucose and hypoxic conditions. (a) Results of representative experiments of ROS production and cell death in HLECs cultured under $<0.14 \%$ atmospheric $\mathrm{O}_{2}$ for $0.5,1.5,2.5$, and $4.0 \mathrm{~h}$ and then reperfused with $5 \mathrm{mM}$ glucose-DMEM under $4 \%$ atmospheric oxygen for $20 \mathrm{~h}$. (b) Results of representative experiments of human LECs proliferation after a short-term BrdU pulse. Left panel show the light photomicrographs of human LECs, middle and right panel represent the BrdU-incorporated cells (proliferating cells) and the EthD-positive cells (apoptotic cells), respectively. Total BrdU- and EthD-positive cells from four separate experiments were counted and are presented as the means \pm S.D. (c) Level of GSH in human LECs cultured in $5 \mathrm{mM}$ glucose-DMEM under $0.14,1,4$, and $20 \%$ atmospheric $0 x y g$ en and GF-DMEM under $<0.14 \%$ atmospheric oxygen for $3 \mathrm{~h}$ and then reperfused with $5 \mathrm{mM}$ glucose-DMEM under $1 \%$ (AN-1), $4 \%$ (AN-4), and $20 \%$ (AN-20) of atmospheric oxygen for $22 \mathrm{~h}$. The results are the means \pm SDs. The experiments were repeated 4 times and were compared between the anoxia treated and untreated human LECs (Student's $t$-tests). 

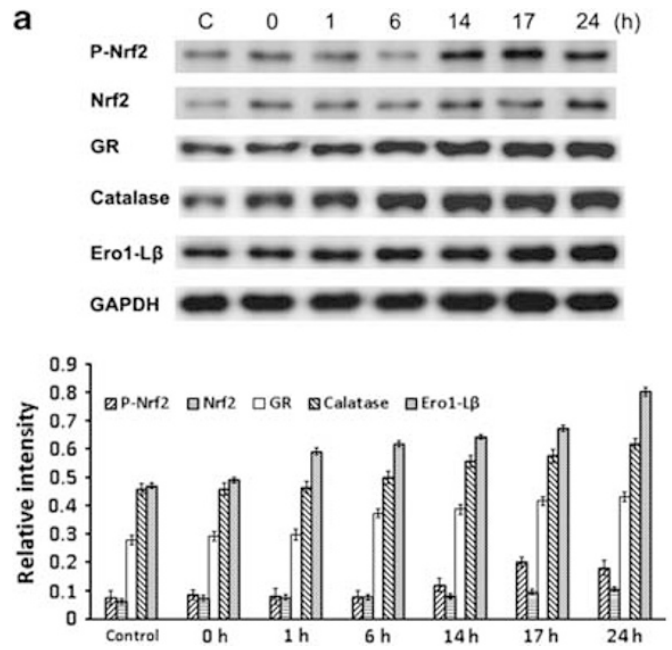
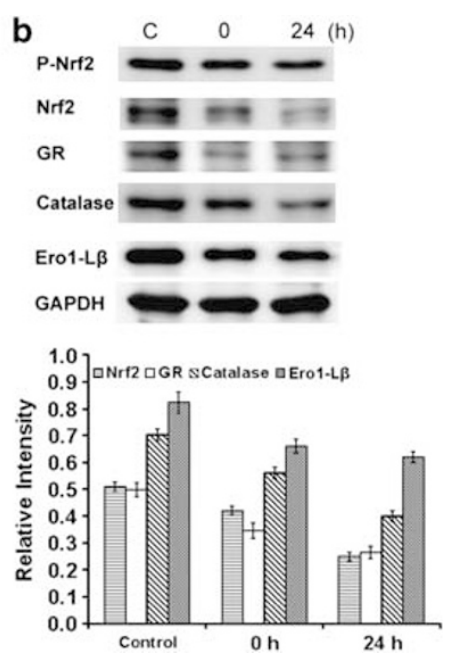

Figure 6 Representative western blot of P-Nrf2, Nrf2, GR, catalase, and Ero1-L $\beta$ of human LECs exposed to $<0.14 \%$ atmospheric oxygen for $3 \mathrm{~h}(\mathbf{a})$ and $5 \mathrm{~h}$ (b) then reperfused with $5 \mathrm{mM}$ glucose-DMEM under $1 \%$ atmospheric $\mathrm{O}_{2}$ for $24 \mathrm{~h}$. Intensity of each band was normalized with intensity of GAPDH

a

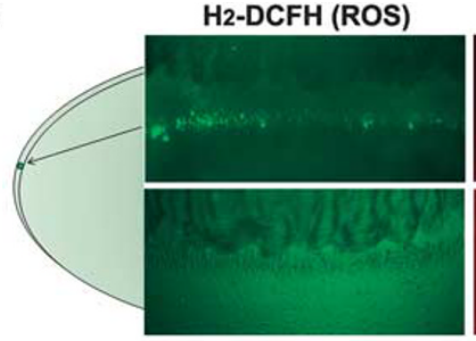

b

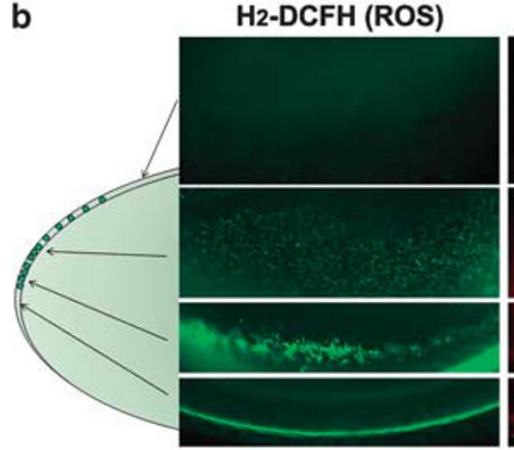

EthD (Cell death)

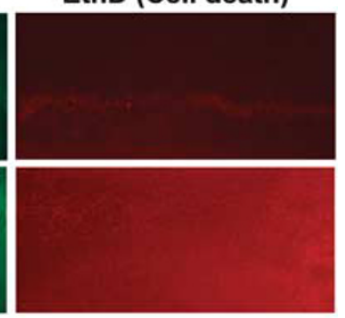

EthD (Cell death)

Figure 7 ROS production and cell death analyses in rat lenses after ischemiareperfusion treatment. Rat lenses exposed to $1 \mathrm{~h} \mathrm{(a)} \mathrm{and} 5 \mathrm{~h}(\mathrm{~b})$ ischemic conditions were cultured in $5 \mathrm{mM}$ glucose-DMEM under $1 \%$ atmospheric oxygen for $22 \mathrm{~h}$. The focal points of the microscope to the lens are indicated on the left

levels of GSH in HLECs cultured in $5 \mathrm{mM}$ glucose-DMEM at $0,1,4$, and $20 \%$ atmospheric oxygen for $22 \mathrm{~h}$. The GSH levels in the HLECs cultured in $0.14 \%$ were lowest, followed by 1 and $4 \%$. The $20 \%$ atmospheric oxygen condition had the highest levels of GSH (Figure $5 \mathrm{c}$ ). These results are consistent with the idea that aerobic respiration generates more ATP and more NADPH in the mitochondria which then produces higher levels of free $\mathrm{GSH}^{37}$

Next, we studied the GSH level in HLECs exposed to GF-DMEM and placed under severe hypoxic conditions for $3 \mathrm{~h}$ and then return to $5 \mathrm{mM}$ glucose-DMEM in 1 , 4 , or $20 \%$ oxygen for $22 \mathrm{~h}$. The results were compared with those

obtained from HLECs cultured at the different atmospheric oxygen levels without the prior treatment with GF-DMEM (Figure 5c). The cells exposed to the GF-DMEM only once had $5 \%$ lower GSH levels than the HLECs cultured in $5 \mathrm{mM}$ glucose-DMEM at comparable oxygen levels. We suggest that multiple exposures to low glucose conditions might lead to significant oxidation of the lenses.

Immunohistochemistry of UPR proteins. The levels of UPR-specific proteins in two groups of four rat lenses treated with ischemia for $3 \mathrm{~h}$ and reperfused for $21 \mathrm{~h}$ were determined. The intensity of immunostaining with antibodies specific to ATF4, Bip, CHOP, PDI, and Ero1-L $\beta$ were significantly increased in the germinative zone, in the LECs that covered the cortical region of the lens, and lens fiber cells at the very early stage of differentiation but not in the central LECs and in matured lens fiber cells. The intensity of immunostaining was also lower in the untreated control lenses (Figure 8a). Interestingly, $\operatorname{Ero1}-\mathrm{L} \beta$ is an oxidative enzyme that is increased by prolonged UPR.

Protein blot analyses of the proteins obtained from an ARC lens showed that most of the UPR proteins are degraded but Ero1-L $\beta$ was still detectable, and its level remained for a long time in the lens fiber cells (data not shown). A diabetic cataractous lens from a 57-year-old individual had a comparatively high intensity of gold particles at a depth of a few millimeters in the cortical lens fiber cells (Figure 8b). We estimated that this region developed in the past 3.5-4 years, which suggests that the UPR-specific oxidative protein, Ero1- $\mathrm{\beta} \beta$ might be accumulated in the LECs produced over the past several years. The control lens did not have the higher intensity of the gold particles. Thus, we were able to see the effects of UPR activation in the human diabetic cataractous lens.

\section{Discussion}

Severe hypoglycemia in patients has been statistically shown to be associated with adverse consequences, although a direct causal relationship has not been demonstrated 
ATF4
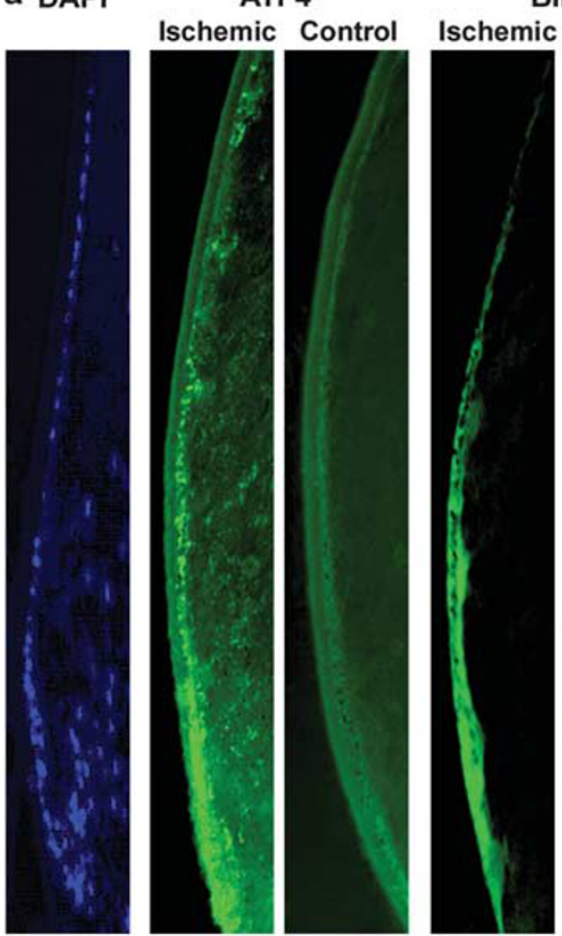

BIP

Control
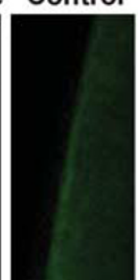

b

3.5-4.0 Years

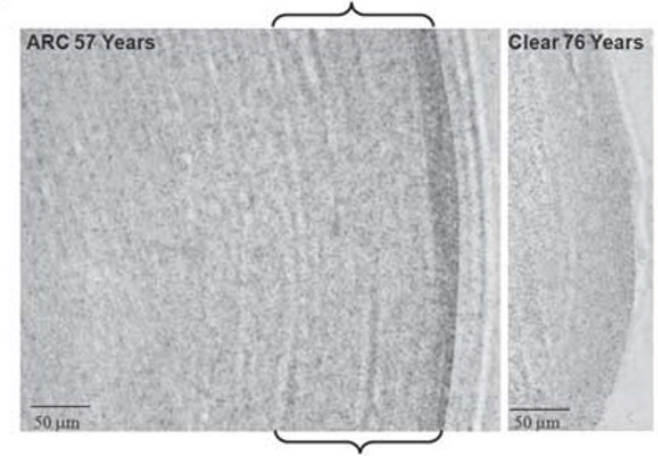

CHOP
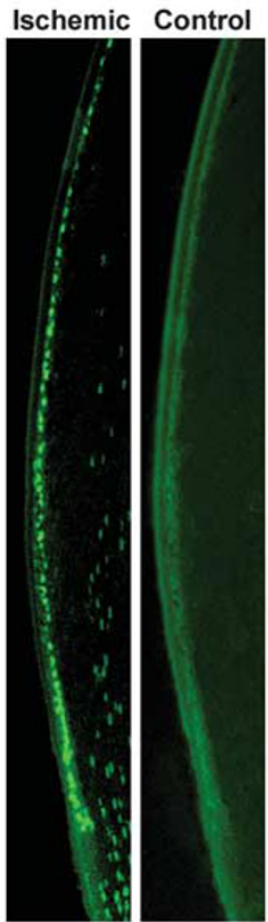

PDI

Ischemic Control
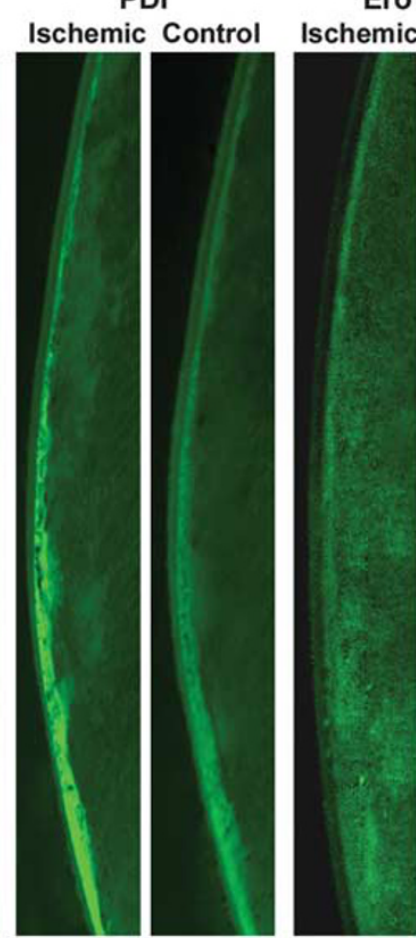

ro1 L- $\beta$

No $\mathrm{Ab}$

C

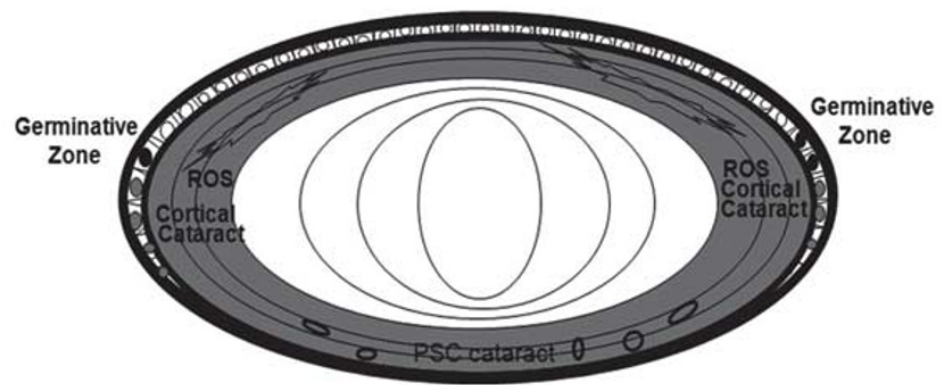

Figure 8 (a) Immunohistochemistry of UPR-specific proteins (ATF4, Bip, CHOP, PDI, and Ero1-L $\beta$ ) in rat lenses exposed to $<0.14 \%$ atmospheric oxygen for $3 \mathrm{~h}$ and reperfused in $5 \mathrm{mM}$ glucose-DMEM at $1 \%$ atmospheric oxygen for $21 \mathrm{~h}$. (b) Immunohistochemistry of a human cortical ARC and a clear lens stained with Ero1-L $\beta$ antibody. (c) Schematic diagram hypothesizes the cortical and posterior sub-capsular cataract formation in diabetic patients

between hypoglycemia and cataracts. Our results showed that a short duration exposure to low glucose conditions activated the protective UPR in HLECs, and prolonged hypoglycemic condition under severe hypoxic condition induced the apoptotic UPR and production of ROS. These changes resulted in lens oxidation, and the death of LECs. Diabetic patients with tight glycemic control by insulin therapy can develop hypoglycemia, in which the glucose level can be $<3 \mathrm{mM}$ in the blood and $\leq 1.5 \mathrm{mM}$ in the vitreous fluid. This is a critical concentration in the lens because the UPR is activated below this concentration. ${ }^{9}$ These observations are consistent with earlier results that diabetic cataracts are strongly associated with age-dependent circulatory disorders, duration of diabetes, elevated glycosylated hemoglobin levels, lower intraocular pressure, and diastolic blood pressure. ${ }^{1,7}$ Furthermore, extreme fasting and metabolic diseases induce hypoglycemia, and our results showed that only $30 \mathrm{~min}$ exposure to low glucose is sufficient to induce the UPR in the LECs in the germinative zone of rat lenses. Generally, hyperglycemia and hyperoxia have been reported to induce lens oxidation and cataracts. ${ }^{38,39}$ We propose that lower than physiological concentrations of glucose and oxygen also induce oxidation of the lens by activating the UPR. Thus, it is highly possible that hypoglycemia is also one of the factors contributing to oxidation in lenses.

Hyperglycemic cataracts have been extensively studied, and the results showed that increased glucose concentrations in the lenses generate hyperosmotic stress. ${ }^{3}$ The hyperosmolarity combined with glycoxidation, increased cytosolic $\mathrm{Ca}^{++}, 5$ cell death, and aging ${ }^{1,7}$ is considered to be the etiological factor that causes diabetic cataracts. ${ }^{8}$ We suggest that low glucose under severe hypoxia induces the apoptotic UPR, which leads to the production of ROS, releases of $\mathrm{Ca}^{++}$from the $\mathrm{ER}$, increases of cytosolic $\mathrm{Ca}^{+}{ }^{+}$, and 
induced apoptosis. However, hypoglycemia activates a very strong UPR within a short time but hyperglycemia requires a prolonged time to induce only a very mild UPR in the lens. The hypoglycemia would be combined with the hyperglycemic conditions rather than act alone, and it is a transient condition that develops in diabetics. Thus, serious damage can be caused by transient hypoglycemia in the lens.

We hypothesized that diabetic individuals develop cortical or posterior sub-capsular cataracts (PSC) because of the induction of the UPR and production of ROS. The lens grows throughout life by generating new fiber cells on the old lens fiber cells. Our studies, ROS increased in the LECs in the germinative zone which differentiate into the cortical fiber cells (Figure 7a). We suggest that these lens fiber cells have less Nrf2 dependent antioxidant protection, and the changes result in oxidation and crystallin aggregation in the cortical and posterior regions (Figure $8 \mathrm{c}$ ). This suggestion is consistent with the earlier finding that diabetic cataracts are strongly associated with the duration of diabetes, ${ }^{1,7}$ that is, longer the diabetes, the thicker is the layer of cortical lens fiber cells.

\section{Materials and Methods}

Human lens epithelial cell (HLEC) Cultures. To examine cell growth, human lens epithelial cells (HLECs; SRA 01/04) ${ }^{31}$ were cultured overnight in $25 \mathrm{mM}$ glucose-Dulbecco's Modified Eagle's Medium (DMEM; Invitrogen Corp., Carlsbad, CA, USA) with $10 \%$ fetal calf serum (FCS) at $37^{\circ} \mathrm{C}$ under $20 \%$ atmospheric oxygen. Before each experiment, the HLECs were pre-cultured overnight in $5 \mathrm{mM}$ glucoseDMEM under $4 \%$ atmospheric oxygen. Some of the HLECs were cultured in glucose free (GF)-DMEM with 10 or $0.2 \%$ FCS at $37^{\circ} \mathrm{C}$ in 1,4 or $20 \%$ atmospheric oxygen. HLECs were also cultured in $<0.14 \%$ atmospheric oxygen by placing the cells in a vacuum bag with AnaeroGen. The 1 and $4 \%$ atmospheric oxygen environments were generated in an $\mathrm{O}_{2} / \mathrm{CO}_{2}$ incubator (Sanyo, Osaka, Japan) with an attached 50 gallon liquid nitrogen gas tank. The $20 \%$ atmospheric oxygen environment was generated in a normal tissue culture incubator.

Rat lens organ culture. Sprague Dawley rats (Charles River Laboratories Inc., Wilmington, MA, USA) were euthanized by $\mathrm{CO}_{2}$, and the eyes were enucleated. The lenses were extracted and cultured in $2 \mathrm{ml}$ of modified medium199 (Lonza eShop, Melnik, Czech Republic) ${ }^{32}$ with penicillin (100 units/ml) and streptomycin (100 units/ml) (Invitrogen Corp., Gland Island, NY, USA) for 20-24 h at $37^{\circ} \mathrm{C}$ under 1 and $4 \%$ atmospheric oxygen.

The experimental procedures used on the rats were approved by the University of Nebraska Animal Care and Use Committee and were in compliance with the Animal Welfare Act (Public Law 91-579) as mandated by the NIH Guide for Care and Use of Laboratory Animals. Clinical veterinary services were provided through the University Nebraska Medical Center, and the procedures recommended by the Association for Research in Vision and Ophthalmology resolution on the use and treatment of animals in ophthalmic and vision research were followed.

Protein blot analysis. Cultured LECs were lysed in RIPA buffer (Cell Signaling Technology, Danvers, MA, USA). A total of $10-20 \mu \mathrm{g} / \mu \mathrm{l}$ of soluble proteins separated by SDS-PAGE were blotted onto nitrocellulose membranes, and the membranes were blocked for $1 \mathrm{~h}$ in a buffer containing $5 \%$ nonfat milk. Then the membranes were incubated with primary antibody overnight at $4^{\circ} \mathrm{C}$, and with secondary antibody at room temperature for $1 \mathrm{~h}$. The membranes were placed in luminol reagent (Santa Cruz Biotechnology, Santa Cruz, CA, USA), and then exposed to X-ray film to view the protein bands. Antibodies to Bip (BD Biosciences, Franklin Lakes, NJ, USA), P-PERK, P-IRE1 $\alpha$, P-elF2 $\alpha$, ATF4, Ero1-L $\beta$, Nrf2, GR, catalase (Santa Cruz Biotechnology), and GAPDH (Novus Biological, Littleton, CO, USA) were purchased. The intensity of each band was normalized to that of GAPDH, and the data are presented as a relative intensity using the ImageJ analysis software. ${ }^{33}$

Cell viability/death and ROS staining. Rat lenses or cultured HLECs were stained with a mixture of two probes; calcein $\mathrm{AM}$ and ethidium homodimer-1 (EthD) (Viability/Cytotoxicity Assay Kits; Biotium Inc., Hayward, CA, USA) for
$30 \mathrm{~min}$ as recommended by the manufacturers. The cytosolic ROS level was determined by adding $1 \mu \mathrm{g} / \mathrm{ml}$ of $2^{\prime}, 7^{\prime}$-dichlorodihydrofluorescein diacetate $\left(\mathrm{H}_{2}-\mathrm{DCFH}\right)$ (Invitrogen Corp., Gland island, NY) into PBS for $40 \mathrm{~min}$ at $20^{\circ} \mathrm{C}$, then washed twice with PBS, followed by fluorescent microscopic imaging (Nikon, Eclipse TE2000-U, Tokyo, Japan). The oxidation of $\mathrm{H}_{2}$-DCFH required cytochrome $c{ }^{34}$ which is present in LECs.

5-Bromo-2-Deoxyuridine (BrdU) labeling. HLECs were cultured with $25 \mathrm{mM}$ glucose-DMEM and $10 \mu \mathrm{g} / \mathrm{ml}$ of BrdU (Sigma Chemicals, St Louis, MO, USA) on a glass cover slides for $30 \mathrm{~min}$. The cells were further cultured in GF-DMEM for an additional $16 \mathrm{~h}$ and then stained with EthD for $30 \mathrm{~min}$. The cells were then fixed with $4 \%$ paraformaldhyde in PBS for $1 \mathrm{~h}$, treated with cold methanol/acetone $(1: 1)$ for $10 \mathrm{~min}$, and then treated with $2 \mathrm{~N} \mathrm{HCl}$ at $37^{\circ} \mathrm{C}$ for $30 \mathrm{~min}$. The cells were washed three times with PBS and incubated in 1:200 diluted Fluor-labeled anti-BrdU antibody for $1 \mathrm{~h}$ to $72 \mathrm{~h}$. Photographs were taken with a camera on a Nikon fluorescent microscope using a red or a green filter.

Glutathione assay. The level of GSH was determined with a GSH quantification Kit (Dojindo Molecular Technologies Inc., Kumamoto, Japan) according to the manufacturer's instructions. Briefly, HLECs $\left(1 \times 10^{6}\right.$ cells $)$ were cultured in 10-cm Petri dishes under different levels of atmospheric oxygen for $20-24 \mathrm{~h}$. The cells were treated with $1 \%$ trypsin for $3 \mathrm{~min}$ and collected by centrifugation at $900 \times \mathrm{g}$ for $10 \mathrm{~min}$ at $4^{\circ} \mathrm{C}$. The cells were washed with $300 \mu \mathrm{l}$ of PBS, then $80 \mu \mathrm{l}$ of $10 \mathrm{mM} \mathrm{HCl}$ was added, and the cells were lysed twice by freezing and thawing. Then, $20 \mathrm{ml}$ of $5 \% 5$-sulfosalicylic acid was added to the lysate, and the mixture was centrifuged at $8000 \times g$ for $10 \mathrm{~min}$. The GSH level was determined by measuring absorbance at $405 \mathrm{~nm}$ in an ELISA reader.

Quantification of glucose and oxygen concentrations. A glucometer (Accutrend Plus with Chemstrip, Roche, Mannheim, Germany) was used to quantify the concentration of glucose in the culture medium, aqueous, and vitreous. A total of $10 \mu \mathrm{l}$ of aqueous was collected from the rat eye, and the glucose level was quantified by applying the fluid to the Chemstip. An oxygen meter (Channel tissue $\mathrm{pO}_{2}$ monitor, Oxford Optronix Ltd, Oxford, UK) was used to measure the oxygen levels. The rat cornea was punctured with a 28-gage needle and a capillary size Bayonet Neill-Concelman cable was inserted into the anterior chamber to measure the oxygen level in the aqueous humor.

Histology and immunohistochemistry. Rat lenses were fixed in $4 \%$ glutaraldehyde, embedded in paraffin, and $7 \mu \mathrm{m}$ sections were cut (Histology Core Facility, UNMC). All of the UPR antibodies were diluted 1/100 times and stained overnight or for 3 days at $4^{\circ} \mathrm{C}$. Cy3-linked secondary antibodies (Amersham, Piscataway, NJ, USA) were diluted to $1 / 1000$ and conjugated to make specific proteins visible by incubating the sections for $1 \mathrm{~h}$ at room temperature. The sections were examined with a fluorescent microscope with a red or green filter.

A human lens with ARC and a clear lens were obtained from the National Disease Research Interchange, Philadelphia, PA, USA, fixed, and embedded into a Lowicryl K4M for 1 week. Thin sections $(1 \mu \mathrm{m})$ were prepared and stained with a rabbit polyclonal antibody to Ero1-L $\beta$ and gold-labeled secondary antibody.

Statistical analysis. The results are expressed as the means \pm S.D., and the significance of differences was evaluated by Student's $t$-tests using SPSS (version 15.0) software (SPSS Inc., Chicago, IL, USA). Values were considered statistically significant when $P<0.05$.

\section{Conflict of Interest}

The authors declare no conflict of interest.

Acknowledgements. This work was supported by the RPB and EY0180172. No additional external funding received for this study. We appreciate the NDRI (Philadelphia, PA) for providing human lenses. We thank Dr. Hamasaki for critically reading the manuscript.

\section{Author Contributions}

RE and TS contributed intellectually to the study design and interpretation, performed the studies, analyzed the data, and wrote the article. PP, CJM, MLM, DWL, AMT, and JU performed laboratory analyses. 
1. Harding JJ. Recent studies of risk factors and protective factors for cataract. Curr Opin Ophthalmol 1997; 8: 46-49.

2. Hegde KR, Varma SD. Cataracts in experimentally diabetic mouse: morphological and apoptotic changes. Diabetes Obes Metab 2005; 7: 200-204.

3. Kinoshita JH. A thirty year journey in the polyol pathway. Exp Eye Res 1990; 50 567-573.

4. Truscott RJ, Augusteyn RC. Oxidative changes in human lens proteins during senile nuclear cataract formation. Biochem Biophys Acta 1977; 492: 43-52.

5. Levy J. Abnormal cell calcium homeostasis in type 2 diabetes mellitus: a new look on old disease. Endocrine 1999; 10: 1-6.

6. Duncan G, Jacob TJ. Calcium and the physiology of cataract. Ciba Found Symp 1984; 106 : 132-152.

7. Negahban K, Chern K. Cataracts associated with systemic disorders and syndromes Curr Opin Ophthalmol 2002; 13: 419-422.

8. Obara Y. [The oxidative stress in the cataract formation]. Nippon Ganka Gakkai Zassh 1995; 99: 1303-1341.

9. Lundquist O, Osterlin S. Glucose concentration in the vitreous of nondiabetic and diabetic human eyes. Graefes Arch Clin Exp Ophthalmol 1994; 232: 71-74.

10. Lacherade JC, Jacqueminet S, Preiser JC. An overview of hypoglycemia in the critically ill. J Diabetes Sci Technol 2009; 3: 1242-1249.

11. Chylack LT Jr., Schaefer FL. Mechanism of "hypoglycemic" cataract formation in the rat lens. II. Further studies on the role of hexokinase instability. Invest Ophthalmol 1976; 15 519-528.

12. Daly LP, Osterhoudt KC, Weinzimer SA. Presenting features of idiopathic ketotic hypoglycemia. J Emerg Med 2003; 25: 39-43.

13. Shui YB, Fu JJ, Garcia C, Dattilo LK, Rajagopal R, McMillan S et al. Oxygen distribution in the rabbit eye and oxygen consumption by the lens. Invest Ophthalmol Vis Sci 2006; 47 $1571-1580$

14. Barbazetto IA, Liang J, Chang S, Zheng L, Spector A, Dillon JP. Oxygen tension in the rabbit lens and vitreous before and after vitrectomy. Exp Eye Res 2004; 78: 917-924.

15. McNulty R, Wang H, Mathias RT, Ortwerth BJ, Truscott RJ, Bassnett S. Regulation of tissue oxygen levels in the mammalian lens. J Physiol 2004; 559: 883-898.

16. Helbig H, Hinz JP, Kellner U, Foerster MH. Oxygen in the anterior chamber of the human eye. Ger J Ophthalmol 1993; 2: 161-164.

17. Bassnett $\mathrm{S}, \mathrm{McNulty} \mathrm{R}$. The effect of elevated intraocular oxygen on organelle degradation in the embryonic chicken lens. J Exp Biol 2003; 206: 4353-4361.

18. Shui YB, Beebe DC. Age-dependent control of lens growth by hypoxia. Invest Ophthalmol Vis Sci 2008; 49: 1023-1029.

19. Holekamp NM, Shui YB, Beebe D. Lower intraocular oxygen tension in diabetic patients: possible contribution to decreased incidence of nuclear sclerotic cataract. Am J Ophthalmol 2006; 141: 1027-1032

20. Hockwin O. Age changes of lens metabolism. Altern Entwickl Aging Dev 1971; 1: 95-129.

21. Mulhern ML, Madson CJ, Danford A, Ikesugi K, Kador PF, Shinohara T. The unfolded protein response in lens epithelial cells from galactosemic rat lenses. Invest Ophthalmol Vis Sci 2006; 47: 3951-3959.

22. Zhang L, Ebenezer PJ, Dasuri K, Fernandez-Kim SO, Francis J, Mariappan N et al. Aging is associated with hypoxia and oxidative stress in adipose tissue: implications for adipose function. Am J Physiol Endocrinol Metab 2011; 301: E599-E607.

23. Tinhofer I, Anether G, Senfter M, Pfaller K, Bernhard D, Hara M et al. Stressful death of T-ALL tumor cells after treatment with the anti-tumor agent Tetrocarcin-A. Faseb J 2002; 16: $1295-1297$
24. Xie Q, Khaoustov VI, Chung CC, Sohn J, Krishnan B, Lewis DE et al. Effect of tauroursodeoxycholic acid on endoplasmic reticulum stress-induced caspase-12 activation. Hepatology 2002; 36: 592-601.

25. Hettmann T, Barton K, Leiden JM. Microphthalmia due to p53-mediated apoptosis of anterior lens epithelial cells in mice lacking the CREB-2 transcription factor. Dev Biol 2000; 222: $110-123$.

26. Tanaka T, Tsujimura T, Takeda K, Sugihara A, Maekawa A, Terada N et al. Targeted disruption of ATF4 discloses its essential role in the formation of eye lens fibres. Genes Cells 1998; $3:$ 801-810.

27. Tu BP, Weissman JS. The FAD- and O(2)-dependent reaction cycle of Ero1-mediated oxidative protein folding in the endoplasmic reticulum. Mol Cell 2002; 10: 983-994.

28. Pagani M, Fabbri M, Benedetti C, Fassio A, Pilati S, Bulleid NJ et al. Endoplasmic reticulum oxidoreductin 1-lbeta (ERO1-Lbeta), a human gene induced in the course of the unfolded protein response. J Biol Chem 2000; 275: 23685-23692.

29. So HS, Kim HJ, Lee JH, Lee JH, Park SY, Park C et al. Flunarizine induces Nrf2-mediated transcriptional activation of heme oxygenase-1 in protection of auditory cells from cisplatin. Cell Death Differ 2006; 13: 1763-1775.

30. Cullinan SB, Diehl JA. PERK-dependent activation of Nrf2 contributes to redox homeostasis and cell survival following endoplasmic reticulum stress. J Biol Chem 2004; 279: 20108-20117.

31. Ibaraki N, Chen SC, Lin LR, Okamoto H, Pipas JM, Reddy VN. Human lens epithelial cell line. Exp Eye Res 1998; 67: 577-585

32. Ikesugi K, Yamamoto R, Mulhern ML, Shinohara T. Role of the unfolded protein response (UPR) in cataract formation. Exp Eye Res 2006; 83: 508-516.

33. Abramoff MD, Magelhaes PJ, Ram SJ. Image Processing with ImageJ. Biophotonics Int 2004; 11: 36-42.

34. Karlsson M, Kurz T, Brunk UT, Nilsson SE, Frennesson $\mathrm{Cl}$. What does the commonly used DCF test for oxidative stress really show? Biochem J 2010; 428: 183-190.

35. Bito LZ, Salvador EV. Intraocular fluid dynamics. II. Postmortem changes in solute concentrations. Exp Eye Res 1970; 10: 273-287.

36. Endo $\mathrm{H}$, Murata $\mathrm{K}$, Mukai M, Ishikawa $\mathrm{O}$, Inoue M. Activation of insulin-like growth factor signaling induces apoptotic cell death under prolonged hypoxia by enhancing endoplasmic reticulum stress response. Cancer Res 2007; 67: 8095-8103.

37. Wei YH, Wu SB, Ma YS, Lee HC. Respiratory function decline and DNA mutation in mitochondria, oxidative stress and altered gene expression during aging. Chang Gung Med J 2009; 32: 113-132.

38. Simpanya MF, Ansari RR, Leverenz V, Giblin FJ. Measurement of lens protein aggregation in vivo using dynamic light scattering in a guinea pig/UVA model for nuclear cataract. Photochem Photobiol 2008; 84: 1589-1595.

39. Simpanya MF, Ansari RR, Suh KI, Leverenz VR, Giblin FJ. Aggregation of lens crystallins in an in vivo hyperbaric oxygen guinea pig model of nuclear cataract: dynamic lightscattering and HPLC analysis. Invest Ophthalmol Vis Sci 2005; 46: 4641-4651.

40. Shinohara T, Ikesugi K, Mulhern ML. Cataracts: role of the unfolded protein response. Med Hypotheses 2006; 66: 365-370.

Cell Death and Disease is an open-access journal published by Nature Publishing Group. This work is licensed under the Creative Commons Attribution-NonCommercial-No Derivative Works 3.0 Unported License. To view a copy of this license, visit http://creativecommons.org/licenses/by-nc-nd/3.0/

Supplementary Information accompanies the paper on Cell Death and Disease website (http://www.nature.com/cddis) 